\title{
A Systematic Review of Research on Self-Sexualization
}

\author{
Kim K. P. Johnson, University of Minnesota \\ Ui-Jeen Yu, Illinois State University
}

Keywords: dress, review, self-sexualization

The American Psychological Association (2007, p.1) task force on the sexualization of girls identified four components of sexualization any one of which is sufficient for sexualization to occur. These components were "(1) a person's value comes only from his or her sexual appeal or behavior, to the exclusion of other characteristics; (2) a person is held to a standard that equates physical attractiveness (narrowly defined) with being sexy; (3) a person is made into a thing for others' sexual use, rather than seen as a person with the capacity for independent action and decision making; and/or (4) sexuality is inappropriately imposed upon a person." Sexualization is key to the concept of self-sexualization. Selfsexualization occurs ${ }^{1}$ when individuals willingly sexualize the self (Choi \& DeLong, 2019).

The self-sexualization of women is an important issue as sexualization is believed to support the low status of women and contribute to body related anxieties and concerns (Smolak \& Murnen, 2011) as well as results in negative perceptions by others (Gurung \& Chrouser, 2007). Not only is sexualization an important issue for women but also for girls. Kapidzic and Herring (2014) utilizing photographic data from a chat site reported that teens' profile pictures often sexualized (i.e., displayed seductive behavior and body-revealing clothing). Similar to adult women, inferences drawn about young girls depicted in sexualized clothing were negative. Specifically, these girls as were rated as less intelligent, competent, determined and capable as well as low in self-respect and morality (Graff, Murnen \& Smolak, 2012) when compared to girls appearing in non-sexualized clothing.

Self-sexualization is an emerging area of research relevant to clothing researchers as evaluations of sexual appeal often stem from specific items and uses of dress. Our research purpose was to systematically review the available research in this area. Reviews are important as they summarize key findings, assist in identifying knowledge gaps, and provide an important foundation for researchers. Research questions were (RQ1) What theories were used in self-sexualization research? (RQ2) What research strategies were utilized in this research? (RQ3) What demographic characteristics describe the participants in this research? (RQ4) What measures of self-sexualization were employed? and (RQ5) What are the major findings?

As the APA task force issued their report on the sexualization in 2007, the time frame for this research was 2007-2020. To locate the data for this research, multiple data bases were searched (e.g., Academic Search Premier, Google Scholar, Web of Science, Psych Info, ABI/INFORM Global, ERIC EBSCO, and ERIC ProQuest) using the following search terms: self-sexualization, self-sexualizing, sexual selfpresentation, and internalized sexualization. Cited reference lists were also reviewed to identify articles (i.e., ancestry approach). The data was limited to refereed journal articles reporting empirical research, published in English, and including self-sexualization as a variable. The final sample consisted of 37 journal articles reporting a total of 42 studies. Thirty-seven studies were used for data analysis after omitting irrelevant studies.

Theories used. Over half of the 37 studies (51.4\%) did not specify a theory or a theoretical framework. Researchers utilizing theory primarily employed objectification theory $(24.3 \%)$ followed by the gender role

\footnotetext{
${ }^{1}$ Additional terms used include sexual self-presentation and internalized sexualization.
} 
development model (8.1\%). The absence of theory is problematic as theory building and application is critical to an area of research.

Research strategies utilized. Researchers primarily employed survey designs (73\%) followed by experiments (16.2\%), content analyses (5.4\%), and focus groups $(2.7 \%)$. One article did not report a research strategy (2.7\%). Over half of the research was conducted in the U.S. (56.8\%), followed by Internet sites $(8.1 \%)$, MTurk (8.1\%), and the Netherlands (5.4\%). Most research was cross-sectional (91.9\%). All studies reported convenience samples (100\%). Reliance on survey designs with convenience samples severely limits generalizability. Experimental designs would be useful in answering research questions tied to causation. Qualitative research strategies would enable identification of additional factors important to the development of self-sexualization as well as outcomes and provide in-depth funderstanding of selfsexualization experiences. Longitudinal research is needed to assess onset and duration of self-sexualization behaviors.

Participant characteristics. Researchers primarily studied college students (40.5\%), followed by nonstudent adults (21.6\%), and junior high school students (10.8\%). Ethnicity of participants was predominantly Caucasian (86.5\%). Understanding of self-sexualization would be strengthened with investigations of a range of ethnicities to determine cultural contributors and inhibitors.

Self-sexualization measures. About half of the studies reported not using existing measures of selfsexualization (32.4\%). Researchers developed their own measures in $18.9 \%$ of the studies, often not assessing the validity of their scales. Six existing measures of self-sexualization were identified: Enjoyment of Sexualization Scale (Liss et al, 2011) (13.5\%), Internalized Sexualization Scale (ISS; McKenney \& Bigler, 2016) (10.8\%), self-sexualization behaviors (Smolak et al., 2014) (8.1\%), self-sexualizing behavior scale (Nowatzki \& Morry, 2009) (5.4\%), sexy online self-presentation scale (Vandenbosch, van Oosten, \& Peter, 2015) (5.4\%), and the Surveillance subscale of the Objectified Body Consciousness Scale (OBCS: McKinley \& Hyde, 1996) (2.7\%). Clear opportunity exists for valid and reliable scale development assessing both attitudinal and behavioral aspects of self-sexualization.

Major findings. Many researchers (37.8\%) were interested in identifying variables that preceded selfsexualizing. Internalized sexualization, body surveillance, body shame, and media consumption (e.g., watching self-sexualizing music videos) strongly predisposed women to engage in self-sexualizing behaviors and appearances. Among adolescents, peer norms and need for popularity predicted willingness to post self-sexualized pictures online. Enjoyment of sexualization, viewing sex as a source of power, and the belief that women are sex objects were also related to self-sexualized appearances and behaviors on social media sites.

Behavioral outcomes (16.2\%) of self-sexualization were also identified and are somewhat inconsistent between girls and women. Self-sexualization was positively related to self-objectification and weight concerns among girls. Girls who self-sexualized tended to wear body-revealing clothing and have parents that held low academic performance expectations for them. However, women who self-sexualized tended to report experiencing sexual empowerment, were likely to report increased self-esteem and self-confidence, increased opportunities for sexual self-expression, positive male attention, and increased freedom for sexual desires,

In sum, our findings reveal predictors and outcomes of self-sexualization. However, none of this research was conducted with probability samples. Opportunities exist in several areas (e.g., theory development, expanding research strategies employed, scale development) to strengthen and build research in this important area.

Page 2 of 3

(c) 2020 The author(s). Published under a Creative Commons Attribution License (https://creativecommons.org/licenses/by/4.0/), which permits unrestricted use, distribution, and reproduction in any medium, provided the original work is properly cited.

ITAA Proceedings, \#77 - https: / /itaaonline.org 


\section{References}

American Psychological Association, Task Force on the Sexualization of Girls. (2007). Report of the APA Task Force on the Sexualization of Girls. Retrieved from http://www.apa.org/pi/women/programs/girls/report-full.pdf Choi, D., \& Delong, M. (2019). Defining female self sexualization for the twenty-first century. Sexuality \& Culture, 23, 1350-1371. doi.org/10.1007/s12119-019-09617-3

Graff, K., Murnen, S. ,\& Smolak, L. (2012). Too sexualized to be taken seriously? Perceptions of a girl in childlike vs. sexualizing clothing. Sex Roles, 66, 764-775.

Gurung, R. A. R., \& Chrouser, C. J. (2007). Predicting objectification: Do provocative clothing and observer characteristics matter? Sex Roles, 57, 91-99.

Kapidzic, S., \& Herring, S. C. (2014). Race, gender, and self-presentation in teen profile photographs. New Media \& Society, 17, 958-976.

Liss, M., Erchull, M. J., \& Ramsey, L. R. (2011). Empowering or oppressing? Development and exploration of the Enjoyment of Sexualization Scale. Personality and Social Psychology Bulletin, 37(1), 5568.

McKenney, S. J., \& Bigler, R. S. (2016). Internalized sexualization and its relation to sexualized appearance, body surveillance, and body shame among early adolescent girls. The Journal of Early Adolescence, 36(2), 171-197.

McKinley, N. M., \& Hyde, J. S. (1996). The objectified body consciousness scale: Development and validation. Psychology of women quarterly, 20(2), 181-215.

Nowatzki, J., \& Morry, M. M. (2009). Women's intentions regarding, and acceptance of, self-sexualizing behavior. Psychology of Women Quarterly, 33(1), 95-107

Smolak, L., \& Murnen, S. K. (2011). The sexualization of women and girls as key antecedents to selfobjectification. In R. Calogero \& J. K. Thompson (Eds.), The objectification of women: Innovative directions in research and practice (pp. 53-75). Washington: American Psychological Association.

Smolak, L., Murnen, S. K., \& Myers, T. A. (2014). Sexualizing the self: What college women and men think about and do to be "sexy". Psychology of Women Quarterly, 38(3), 379-397.

Vandenbosch, L., van Oosten, J. M., \& Peter, J. (2015). The relationship between sexual content on mass media and social media: A longitudinal study. Cyberpsychology, Behavior, and Social Networking, 18(12), 697-703.

Page 3 of 3

(c) 2020 The author(s). Published under a Creative Commons Attribution License (https://creativecommons.org/licenses/by/4.0/), which permits unrestricted use, distribution, and reproduction in any medium, provided the original work is properly cited.

ITAA Proceedings, \#77 - https: //itaaonline.org 